\title{
Role-Modeling Cost-Conscious Care-A National Evaluation of Perceptions of Faculty at Teaching Hospitals in the United States
}

\author{
Mitesh S. Patel, MD, MBA, MS ${ }^{1,2,3}$, Darcy A. Reed, MD, MPH', Cynthia Smith, MD ${ }^{5}$, and Vineet $M$. \\ Arora, MD, MAPP' \\ ${ }^{1}$ Center for Health Equity Research and Promotion, Veterans Affairs Medical Center, Philadelphia, PA, USA; ${ }^{2}$ Perelman School of Medicine, \\ University of Pennsylvania, Philadelphia, PA, USA; ${ }^{3}$ The Wharton School, University of Pennsylvania, Philadelphia, PA, USA; ${ }^{4}$ Division of Primary Care \\ Internal Medicine, Mayo Clinic, Rochester, MN, USA; ${ }^{5}$ American College of Physicians, Philadelphia, PA, USA; '́Section of General Internal \\ Medicine, University of Chicago, Chicago, IL, USA.
}

BACKGROUND: Little is known about how well faculty at teaching hospitals role-model behaviors consistent with cost-conscious care.

OBJECTIVE: We aimed to evaluate whether residents and program directors report that faculty at their program consistently role-model cost-conscious care, and whether the presence of a formal residency curriculum in costconscious care impacted responses.

DESIGN: Cost-conscious care surveys were administered to internal medicine residents during the 2012 Internal Medicine In-Training Examination and to program directors during the 2012 Association of Program Directors in Internal Medicine Annual Survey. Respondents stated whether or not they agreed that faculty in their program consistently role-model cost-conscious care. To evaluate a more comprehensive assessment of faculty behaviors, resident responses were matched with those of the director of their residency program. A multivariate logistic regression model was fit to the outcome variable, to identify predictors of responses that faculty do consistently rolemodel cost-conscious care from residency program, resident, and program director characteristics.

PARTICIPANTS: Responses from 12,623 residents (58.4\% of total sample) and 253 program directors $(68.4 \%)$ from internal medicine residency programs in the United States were included.

MAIN MEASURES: The primary outcome measure was responses to questionnaires on faculty role-modeling cost-conscious care.

KEY RESULTS: Among all responses in the final sample, $6,816(54.0 \%)$ residents and $121(47.8 \%)$ program directors reported that faculty in their program consistently role-model cost-conscious care. Among paired responses of residents and their program director, the proportion that both reported that faculty do consistently rolemodeled cost-conscious care was $23.0 \%$ for programs with a formal residency curriculum in cost-conscious care, $26.3 \%$ for programs working on a curriculum, and $23.7 \%$ for programs without a curriculum. In the adjusted model, the presence of a formal curriculum in costconscious care did not have a significant impact on survey responses (odds ratio [OR], 1.04; $95 \%$ Confidence Interval $[C I], 0.52-2.06 ; p$ value $[p]=0.91)$.

CONCLUSIONS: Responses from residents and program directors indicate that faculty at US teaching hospitals

Published online July 15, 2015 were not consistently role-modeling cost-conscious care. The presence of a formal residency curriculum in costconscious care did not impact responses. Future efforts should focus on placing more emphasis on faculty development and on combining curricular improvements with institutional interventions to adapt the training environment.

KEY WORDS: cost-conscious care; high-value ; role-modeling; resident; program director; residency program; teaching hospitals; faculty; medical education.

J Gen Intern Med 30(9):1294-8

DOI: $10.1007 / \mathrm{s} 11606-015-3242-5$

๑) Society of General Internal Medicine 2015

\section{INTRODUCTION}

Improving health care value has become a national priority of health care reform, as the United States aims to improve the quality of care that is delivered while making it more affordable for the general population. ${ }^{1}$ Medical education plays a key role in training the future physician workforce to be good stewards of health care resources. ${ }^{2-5}$ The Accreditation Council for Graduate Medical Education (ACGME) has taken several steps to improve residency training in cost-conscious care. The 2013 internal medicine reporting milestones include a competency-based evaluation of skills in cost-conscious care. ${ }^{6}$ The new Clinical Learning Environment Review (CLER) also examines the extent to which residents receive training in overuse and misuse in the diagnosis or treatment of patients. $^{7}$

Physicians begin to form habits during residency training that may impact their future practice patterns. ${ }^{8}$ More experienced faculty physicians at teaching hospitals serve as rolemodels for trainees. ${ }^{9-11}$ However, many faculty physicians trained in a culture that did not place as much emphasis on reducing unnecessary costs of care; therefore, they must adapt their own teaching methods and practice patterns to better influence trainees to be good stewards of health care resources. $^{12,13}$ Given the significant impact of faculty behavior on resident practice patterns, ${ }^{9-11}$ it is of vital importance to understand whether faculty are appropriately role-modeling cost-conscious care. 
The objective of this study was to evaluate whether residents and program directors report that faculty at their program consistently role-model cost-conscious care, and whether the presence of a formal residency curriculum in cost-conscious care impacted responses.

\section{METHODS}

This study was approved by the Institutional Review Board at the Mayo Clinic.

\section{Study Sample}

The sample comprised 12,623 residents at internal medicine residency programs in the United States and 253 program directors who were members of the Association of Program Directors in Internal Medicine (APDIM).

\section{Data}

Residents were surveyed through a questionnaire developed by the American College of Physicians (ACP) and cosponsored by the Association of Professors in Medicine and APDIM.$^{14}$ The questionnaire was administered to residents by paper during the Internal Medicine In-Training Examination in October 2012. Residents were asked to rate their response (agree strongly, agree somewhat, neutral, disagree somewhat, or disagree strongly) to the following statement: "Faculty who work with residents in my program consistently role-model high-value, cost-conscious care." To develop binary variable representing positive or negative perceptions of role-modeling cost-conscious behaviors, responses of "agree strongly" or "agree somewhat" were coded as " 1 " and all other responses were coded as " 0 ," a method used in prior evaluation of response to a cost-conscious care questionnaire. ${ }^{15}$

Program directors were surveyed through a costconsciousness questionnaire administered electronically by APDIM in August 2012. ${ }^{15,16}$ Program directors were asked to rate their response (agree strongly, agree somewhat, neutral, disagree somewhat, or disagree strongly) to the following statement: "The majority of faculty who work with residents in our program consistently role-model cost-conscious care." To develop binary variable representing positive or negative perceptions of role-modeling cost-conscious behaviors, responses of "agree strongly" or "agree somewhat" were coded as " 1 " and all other responses were coded as " 0 ," a method used in prior evaluation of response to a cost-conscious care questionnaire. ${ }^{15}$ Program directors were also asked whether their residency program had a formal curriculum in costconscious care.

To evaluate a more comprehensive assessment of faculty behaviors, resident responses were matched with those of the director of their residency program. Among 370 residency programs, 261 program directors $(70.5 \%)$ responded to the cost-consciousness questionnaire. Among 21,617 US internal medicine residents, 18,102 (83.7 \%) completed the questionnaire during the Internal Medicine In-Training Examination. Residency programs were excluded if the program director did not respond to the question on faculty role-modeling or if they were located outside of the US ( $n=3,714$ resident responses). Residents were excluded if they did not respond to the faculty role-modeling question ( $n=3,515$ responses), attended a residency program outside of the United States $(n=1,689$ responses), or were not in an internal medicine residency program ( $n=76$ responses). The final sample comprised paired responses from 12,623 residents $(58.4 \%)$ and 253 program directors $(68.4 \%)$. To identify predictors of responses that faculty do consistently role-model cost-conscious care, publicly available data were obtained from the Census Bureau, ${ }^{17}$ the American Medical Association Fellowship Residency Electronic Interactive Database Access System, ${ }^{18}$ and the Accreditation Council for Graduate Medical Education. ${ }^{19}$

\section{Outcome Measures}

The primary outcome measure was responses to questionnaires on faculty role-modeling cost-conscious care.

\section{Statistical Analysis}

Descriptive statistics were conducted to evaluate responses among residents and program directors for programs with a formal residency curriculum in cost-conscious care, without a formal curriculum but working to implement one, and those without a formal curriculum.

A multivariable logistic regression model was fit to the main outcome measure. The model used the resident as the unit of analysis, because each program has only one program director with one response, but has multiple residents with different responses. Rather than defining programs as having or not having faculty that role-model cost-conscious care (which would require arbitrarily setting a cutoff point for the percentage of responses that define a program with faculty that role-model these behaviors), a logistic regression model allows us to account for differing responses by residents within the same program and provides more power to identify predictors of responses. Independent variables were included in the model to evaluate for predictors of the main outcome measure for resident characteristics (gender, post-graduate year, location of medical school training), program director characteristics (gender, academic rank), and program characteristics (presence of a formal curriculum in cost-conscious care, program type, census region). These variables were selected based on prior work ${ }^{15}$ and data availability. Standard errors in the model were adjusted to account for clustering by residency program. ${ }^{20,21}$ Sensitivity analyses were performed by independently evaluating the model using the outcome measure of only perceptions of internal medicine residents and only perceptions of internal medicine program directors. All analyses were conducted using Stata (Version 12, StataCorp, College Station, TX). 


\section{RESULTS}

Characteristics of the resident and program director samples are displayed in Table 1. Among all responses in the final sample, 6,816 (54.0\%) residents and 121 (47.8\%) program directors reported that faculty in their program consistently role-model cost-conscious care. Among program directors. 37 $(14.6 \%)$ reported that their program had a formal curriculum in cost-conscious care, $127(50.2 \%)$ did not but stated they were working on it, and 89 (35.2\%) did not have a curriculum and were not working on implementing one. The percentage of residents and their program director who both reported that they agreed that faculty consistently role-modeled cost-conscious care was $23.0 \%$ for programs with a formal curriculum in cost-conscious care, $26.3 \%$ for programs working on a curriculum, and $23.7 \%$ for programs without a curriculum.

In the adjusted model, the presence of a formal curriculum in cost-conscious care did not have a significant impact on survey responses (odds ratio [OR], 1.04; $95 \%$ Confidence Interval $[\mathrm{CI}], 0.52-2.06 ; p$ value $[p]=0.91$ ) (Table 2). Responses had higher odds of stating that faculty did rolemodel cost-conscious care in residency programs that were community-based (OR, 3.20; $95 \% \mathrm{CI}, 1.53-6.71 ; p<0.01$ ), community-based, university-affiliated (OR, 1.80; $95 \% \mathrm{CI}$, $1.10-2.95 ; p=0.02)$ and located in the South (OR, 2.09; $95 \%$ CI, $1.15-3.80 ;=0.02$ ). Each of these findings was supported by sensitivity analyses evaluating responses of residents and program directors independently.

\section{DISCUSSION}

In this study, we evaluated whether residents and their program directors reported that faculty in their program rolemodeled behaviors consistent with cost-conscious care. To our knowledge, this is the first study to evaluate this issue at a national level. We found that only about one-fourth of the time did both the resident and their program directors report that faculty consistently role-modeled cost-conscious care. A formal curriculum in cost-conscious care did not impact responses positively or negatively. Our findings may offer insights into current training environments and potential opportunities for improvement. Faculty development focused on improving faculty role-modeling of cost-conscious behavior will be necessary to adequately prepare residents to be good stewards of health care resources. ${ }^{22}$ This may be a challenging endeavor, given that practice patterns of experienced physicians are difficult to change, and historically there has been limited funding for faculty development compared to other educational initiatives. ${ }^{23}$

We found that residents and program directors in community-based programs were more likely to report that faculty role-modeled cost-conscious care when compared to university-based programs. These findings may reflect a difference in the culture and training environment between these types of hospitals. More sick or complicated patients may require more costly tests and interventions. If faculty at university-based hospitals are more likely to care for sicker patients, then their practice habits may reflect more intensive use of resources even when less sick patients are admitted. Faculty at community-based hospitals may have different financial incentives than faculty at university-based hospitals. For example, community-based hospitals are more likely to be for-profit. ${ }^{24}$ Therefore, faculty at for-profit community-based hospitals may have different institutional and financial factors affecting their practice patterns than faculty at non-profit university-based hospitals. There may be additional cultural differences between university and community-based programs that also contribute to this difference.

A growing number of residency programs are adopting a formal curriculum in cost-conscious care that includes teaching and assessment of resident knowledge of the impact of their practice on health care costs. ${ }^{15,25}$ We found that compared to programs without a formal curriculum, residents and program directors in training programs with such a curriculum did not have significantly different responses. This may be due to a lack of a curricular effect. Evidence suggests that current

Table 1. Characteristics of the Study Samples

\begin{tabular}{|c|c|c|c|c|c|c|}
\hline Characteristic, N (\%) & Description & PGY-1 & PGY-2 & PGY-3 & All residents & $\begin{array}{l}\text { Program } \\
\text { directors }\end{array}$ \\
\hline All & - & $4,265(100.0)$ & $4,403(100.0)$ & $3,955(100.0)$ & $12,623(100.0)$ & $253(100.0)$ \\
\hline Gender & Male & $2,438(57.2)$ & $2,451(55.7)$ & $2,155(54.5)$ & $7,044(55.8)$ & $174(68.8)$ \\
\hline Medical school location & United States & $2,567(60.2)$ & $2,786(63.3)$ & $2,379(60.2)$ & $7,732(61.3)$ & - \\
\hline \multirow[t]{5}{*}{ Census region } & Midwest & $1,030(24.2)$ & $1,069(24.3)$ & $1,001(25.3)$ & $3,100(24.6)$ & $59(23.3)$ \\
\hline & Northeast & $1,466(34.4)$ & $1,515(34.4)$ & $1,311(33.1)$ & $4,292(34.0)$ & $82(32.4)$ \\
\hline & South & $1,154(27.1)$ & $1,138(25.8)$ & $1,073(27.1)$ & $3,365(26.7)$ & $69(27.3)$ \\
\hline & West & $569(13.3)$ & $644(14.6)$ & $532(13.5)$ & $1,745(13.8)$ & $40(15.8)$ \\
\hline & Unincorporated & $46(1.1)$ & $37(0.8)$ & $38(1.0)$ & $121(1.0)$ & $3(1.2)$ \\
\hline \multirow{4}{*}{ Program type } & Community-based & $231(5.4)$ & $193(4.4)$ & $185(4.7)$ & 609 (4.8) & $20(7.9)$ \\
\hline & $\begin{array}{l}\text { Community-based, University- } \\
\text { affiliated }\end{array}$ & $1,862(43.7)$ & $1,705(38.7)$ & $1,572(39.7)$ & $5,139(40.7)$ & $135(53.4)$ \\
\hline & University-based & $2,078(48.7)$ & $2,452(55.7)$ & $2,139(54.1)$ & $6,669(52.8)$ & $93(36.8)$ \\
\hline & Military-based & $94(2.2)$ & $53(1.2)$ & $59(1.5)$ & $206(1.6)$ & $5(2.0)$ \\
\hline \multirow[t]{3}{*}{ Academic rank } & Professor & - & - & - & - & $70(27.7)$ \\
\hline & Associate Professor & - & - & - & - & $98(38.7)$ \\
\hline & Other & - & - & - & - & $80(31.6)$ \\
\hline
\end{tabular}


Table 2. Adjusted Odds of Residents and their Program Directors Reporting that the Majority of Faculty Working with Residents in their Program Consistently Do Role-Model Cost-Conscious Care

\begin{tabular}{|c|c|c|c|c|}
\hline Domain & Component & Measure & $\begin{array}{l}\text { Odds } \\
\text { ratio(95 \% CI })\end{array}$ & $p$ Value \\
\hline \multirow[t]{12}{*}{ Residency program } & \multirow{3}{*}{$\begin{array}{l}\text { Presence of a formal cost-conscious } \\
\text { care curriculum }\end{array}$} & Yes & $1.04(0.52-2.06)$ & 0.91 \\
\hline & & No, but working on it & $1.17(0.72-1.90)$ & 0.52 \\
\hline & & No & - & - \\
\hline & \multirow[t]{4}{*}{ Program type } & Community-based & $3.20(1.53-6.71)$ & $<0.01$ \\
\hline & & Community-based, university affiliated & $1.80(1.10-2.95)$ & 0.02 \\
\hline & & Military-based & $0.36(0.04-3.30)$ & 0.36 \\
\hline & & University-based & - & - \\
\hline & \multirow[t]{5}{*}{ Census region } & Midwest & $1.71(0.96-3.07)$ & 0.07 \\
\hline & & South & $2.09(1.15-3.80$ & 0.02 \\
\hline & & West & $1.63(0.81-3.27)$ & 0.17 \\
\hline & & Other & $3.04(0.40-22.91)$ & 0.28 \\
\hline & & Northeast & - & - \\
\hline \multirow{7}{*}{ Resident } & \multirow{2}{*}{ Gender } & Male & $0.96(0.87-1.05)$ & 0.35 \\
\hline & & Female & - & - \\
\hline & \multirow[t]{3}{*}{ Post-graduate year } & 3 & $0.96(0.84-1.09)$ & 0.49 \\
\hline & & 2 & $0.96(0.85-1.09)$ & 0.54 \\
\hline & & 1 & - & - \\
\hline & \multirow[t]{2}{*}{ Medical school training location } & International & $1.39(1.04-1.87)$ & 0.03 \\
\hline & & US & - & - \\
\hline \multirow[t]{5}{*}{ Program director } & \multirow[t]{2}{*}{ Gender } & Male & $0.76(0.49-1.20)$ & 0.24 \\
\hline & & Female & - & - \\
\hline & \multirow[t]{3}{*}{ Academic rank } & Professor & $1.42(0.80-2.51)$ & 0.23 \\
\hline & & Associate Professor & $1.01(0.58-1.74)$ & 0.98 \\
\hline & & Other & - & - \\
\hline
\end{tabular}

curricular efforts focus more on resident training through lectures and didactic sessions, and place less emphasis on faculty development. ${ }^{15}$ While core program faculty may help to teach these sessions, it may be the case that many other faculty members are less involved. Generally, there is a need for more research to evaluate and identify medical education interventions to change resident and faculty behavior. ${ }^{26}$ In some cases, technological interventions, such as changes to clinical decision support, may need to be combined with educational interventions to be effective. ${ }^{27}$ It may be possible, although we believe less likely, that cost-conscious curricula led to an awareness effect that offset any positive curricular effect. In that case, residents trained in cost-conscious care may be more aware of these behaviors and have increased recognition of them (or the lack thereof) among faculty.

Several resources exist for internal medicine residency programs to implement cost-conscious care curricula, such as the High Value Care Curriculum developed by the Alliance for Academic Internal Medicine and the American College of Physicians, which is available free online. ${ }^{25,28}$ Based on the findings of this study, medical educators should look for ways to better incorporate faculty development at their institution when implementing these curricula. Increased adoption of such curricula at a national level, along with robust evaluation and iteration of teaching and assessment methods, will be important to increase their impact on practice patterns. However, if the goal is to effectively change faculty and resident behavior, educational efforts may need to be combined with changes at the institutional level. ${ }^{29}$

The training environment has been found to significantly influence physician behavior, specifically with regard to practicing cost-conscious care. ${ }^{8,30}$ Therefore, hospitals and teaching institutions should look for opportunities to demonstrate values and beliefs that model cost-conscious care. Such a model would celebrate restraint and promote physicians who act as good stewards of health care resources. ${ }^{5,12}$ Improving the provision of health service information, such as price transparency, could help to better equip physicians with the information they need to make higher value recommendations for their patients. Two recent studies have demonstrated that displaying costs in the electronic order entry system reduced the ordering of lab tests. ${ }^{31,32}$ Hospitals could improve the availability of, and potentially even require participation in, continuing medical education focused on cost-conscious care. Technology could be utilized to help disseminate best practices and educational materials from hospitals with demonstrated success in this area to institutions with fewer resources. However, it is important that any such faculty development efforts should be rigorously evaluated to determine not only their influence on practice patterns and resident teaching, but also on patient outcomes.

While institutional efforts are important, a coordinated national effort may also be warranted. The ACGME has already incorporated skills in cost-conscious care as part of the internal medicine reporting milestones and CLER. ${ }^{6,7}$ Similarly, specialty boards could use Maintenance of Certification to promote training and mastery of cost-conscious care among faculty physicians. Several non-profit organizations are raising awareness of factors that contribute to health care costs and are looking for innovative solutions. One example is Costs of Care, which in conjunction with the ABIM Foundation, conducted the Teaching Value and Choosing Wisely Challenge. ${ }^{33}$ 
Our study is subject to several limitations. First, as with any survey evaluation, our analysis is limited because of nonresponse bias, although response rates to both surveys are high. Second, our study was limited to residents and programs directors in internal medicine, and therefore generalizability to other specialties may be limited. Third, we evaluated survey responses on faculty behavior, which may vary from actual behavior. While responses among residents and program directors are an important indicator of faculty practice, other measures more directly associated with cost-conscious behavior may add further insights. Fourth, interpretation among survey respondents of terms such as "cost-conscious" and "high-value" may vary, and this variation may contribute to our findings. Finally, this study was not designed to evaluate causal effects and reports only associations.

In conclusion, responses from residents and program directors indicate that faculty at US teaching hospitals were not consistently role-modeling cost-conscious care. The presence of a formal residency curriculum in cost-conscious care did not impact responses. Future efforts should focus on placing more emphasis on faculty development and combining curricular improvements with institutional interventions to adapt the training environment.

Acknowledgements: Dr. Patel was supported in part by the Department of Veteran Affairs and the Robert Wood Johnson Foundation. The funding sources had no role in the design and conduct of the study; collection, management, analysis, and interpretation of the data; and preparation, review, or approval of the manuscript; and decision to submit the manuscript for publication.

Conflict of Interest: Dr. Cynthia Smith is an employee of the American College of Physicians and discloses owning stock in Merck and Company, where her husband is employed. Dr. Vineet Arora receives grant funding from ABIM Foundation and is affiliated with the nonprofit Costs of Care. All other authors declare that they do not have a conflict of interest.

Corresponding Author: Mitesh S. Patel, MD, MBA, MS; Medicine and Health Care Management, University of Pennsylvania, Philadelphia, PA, USA (e-mail: mpatel@upenn.edu).

\section{REFERENCES}

1. Hackbarth G, Boccuti C. Transforming graduate medical education to improve health care value. N Engl J Med. 2011;364(8):693-695.

2. Cooke M. Cost-consciousness in patient care-What is medical education's responsibility? N Engl J Med. 2010;362(14):1253-1255.

3. Weinberger SE. Providing high-value, cost-conscious care: a critical seventh general competency for physicians. Ann Intern Med. 2011;155(6):386-388.

4. Brook RH. The role of physicians in controlling medical care costs and reducing waste. J Am Med Assoc. 2011;306(6):650-651.

5. Korenstein D, Smith CD. Celebrating minimalism in residency training. JAMA Intern Med. 2014;174(10): 1649-1650.

6. Caverzagie KJ, Iobst WF, Aagaard EM, Hood S, Chick DA, Kane GC, Brigham TP, Swing SR, Meade LB, Bazari H, Bush RW, Kirk LM, Green ML, Hinchey KT, Smith CD. The internal medicine reporting milestones and the next accreditation system. Ann Intern Med. 2013;158(7):557-559.

7. Accreditation Council for Graduate Medical Education. CLER pathways to excellence. Available online at: http://www.acgme.org/acgmeweb/Portals / 0/PDFs/CLER/CLER_Brochure.pdf. Accessed 6 Feb 2015.
8. Sirovich BE, Lipner RS, Johnston M, Holmboe ES. The association between residency training and internists' ability to practice conservatively. JAMA Intern Med. 2014; 174(10): 1640-1648.

9. Benbassat $\mathbf{J}$. Role modeling in medical education: the importance of a reflective imitation. Acad Med. 2014;89(4):1-5.

10. Cruess SR, Cruess RL, Steinert Y. Role modelling-making the most of a powerful teaching strategy. BMJ. 2008;336:718-721.

11. Wright S, Wong A, Newill C. The impact of role models on medical students. J Gen Intern Med. 1997;12:53-56.

12. Detsky AS, Verma AA. A new model for medical education: celebrating restraint. J Am Med Assoc. 2012;308(13):1329-1330.

13. Kenny NP, Mann KV, MacLeod H. Role modeling in physicians' professional formation: reconsidering an essential but untapped educational strategy. Acad Med. 2003;78:1203-1210.

14. American College of Physicians. Internal Medicine In-Training Examination. Available online at: http://www.acponline.org/education_recertification/education/in_training/. Accessed 6 Feb 2015.

15. Patel MS, Reed DA, Loertscher L, McDonald FS, Arora VM. Teaching residents to provide cost-conscious care - A national survey of residency program directors. JAMA Intern Med. 2014;174(3):470-472.

16. Alliance for Academic Internal Medicine. APDIM Survey Data. Available online at: http://www.im.org/p/cm/ld/fid=506. Accessed 6 Feb 2015.

17. United States Census Bureau. Data Tools and Apps. Available online at: http://www.census.gov/data/data-tools.html. Accessed 6 Feb 2015.

18. American Medical Association. FREIDA Online. Available online at: http:// www.ama-assn.org/ama/pub/education-careers/graduate-medical-education/freida-online.page. Accessed 6 Feb 2015.

19. Accreditation Council for Graduate Medical Education. Available online at: http://www.acgme.org/. Accessed 6 Feb 2015.

20. Rogers WH. Regression standard errors in clustered samples. Stata Tech Bull Rep. 1993;3:88-94.

21. Williams RL. A note on robust variance estimation for cluster-correlated data. Biometrics. 2000;56:645-646.

22. Wilkerson L, Irby DM. Strategies for improving teaching practices: a comprehensive approach to faculty development. Acad Med. 1998;73(4):387-396

23. Rich EC, Liebow M, Srinivasan M, Parish D, Wolliscroft JO, Fein O, Blaser R. Medicare financing of graduate medical education. J Gen Intern Med. 2002;17(4):283-292.

24. American Hospital Association. Fast facts on US Hospitals. Available online at: http://www.aha.org/research/rc/stat-studies/fast-facts.shtml. Accessed 6 Feb 2015.

25. Smith CD. Teaching high-value, cost-conscious care to residents: The Alliance for Academic Internal Medicine-American College of Physicians curriculum. Ann Intern Med. 2012;157(4):284-286.

26. Asch DA, Weinstein DF. Innovation in medical education. N Engl J Med. 2014;371(9):794-795.

27. Patel MS, Day S, Small DS, Howell JT, Lautenbach GL, Nierman EH, Volpp KG. Using default options within the electronic health record to increase the prescribing of generic-equivalent medications: a quasiexperimental study. Ann Intern Med. 2014;161:S44-S52.

28. Patel MS, Davis MM, Lypson ML. The VALUE framework: training residents to provide value-based care for their patients. J Gen Intern Med. 2012;27:1210-1214.

29. Levy AE, Shah NT, Moriates C, Arora VM. Fostering value in clinical practice among future physicians: time to consider COST. Acad Med. 2014;89(11): 1440 .

30. Chen C, Petterson S, Phillips R, Bazemore A, Mullan F. Spending patterns in region of residency training and subsequent expenditures for care provided by practicing physicians for medicare beneficiaries. JAMA. 2014;312(22):2385-2393.

31. Feldman LS, Shihab HM, Thiemann D, Yeh H, Ardolino M, Mandell S. Impact of providing fee data on laboratory test ordering: a controlled clinical trial. JAMA Intern Med. 2013;173(10):903-908.

32. Horn DM, Koplan KE, Senese MD, Orav EJ, Sequist TD. The impact of cost displays on primary care physician laboratory test ordering. J Gen Intern Med. 2014;29(5):708-714

33. Shah N, Levy AE, Moriates C, Arora VM. Wisdom of the crowd: bright ideas and innovations from the teaching value and choosing wisely challenge. Acad Med. 2015. Available online at: http://journals.lww.com/ academicmedicine/Abstract/publishahead/Wisdom_of_the_Crowd Bright_Ideas_and_Innovations.98880.aspx. Accessed 6 Feb 2015. 